\title{
What is meant by the term "schedule-induced," and how general is schedule induction?
}

\author{
T. J. ROPER \\ School of Biology, University of Sussex, Brighton BN1 9QG, England
}

\begin{abstract}
The term "schedule-induced" implies that the overall frequency of a behavior is greater in the presence of an intermittent schedule of reinforcement than in the absence of such a schedule. Consequently, the occurrence of interreinforcement behavior is not in itself sufficient evidence of schedule induction: a test of induction requires comparison between an intermittent-schedule condition and a nonschedule baseline. The relative merits of different types of nonschedule baseline are examined, and it is concluded that the best test of schedule-induction involves both an extinction and a massed-reinforcer baseline. A working definition of schedule-induction is suggested on this basis. Studies purporting to show schedule induction of activities other than drinking are critically reviewed, and it is concluded that schedule induction may be less general than is usually supposed. It may therefore be more fruitful to seek an explanation of scheduleinduced drinking which focuses specifically on the interaction between food and water ingestion in the rat, rather than an explanation involving concepts such as stress, frustration, or arousal.
\end{abstract}

Falk (1961) showed that when rats were allowed to earn food according to an intermittent variableinterval (VI) 1-min schedule they developed the habit of drinking a small amount of water immediately after ingesting each pellet of food. Because the rats' cumulative intake of water was surprisingly large, Falk referred to this type of drinking as "scheduleinduced polydipsia," or "SIP" for short. SIP is puzzling to physiologists because it challenges a regulatory account of water intake, and to psychologists because, although it is generated by intermittent schedules of reinforcement (and also by intermittent noncontingent delivery of a reinforcer ${ }^{1}$ ), it appears not to arise through a process of adventitious reinforcement or classical conditioning (see reviews by Falk, 1969, 1971; Segal, 1972; Staddon, 1977).

Numerous hypotheses have been proposed to explain the occurrence of SIP, but none seems consistent with all the available data. But perhaps worse than the lack of an adequate detailed account of SIP is the lack of agreement about what general form of explanation should be sought. The purpose of the present paper is to discuss different types of explanation, and to ask which type seems most appropriate on the basis of available evidence.

I have argued elsewhere that attempts to explain schedule-induced drinking have fallen broadly into two categories, termed "thirst" explanations and "general activation" explanations, respectively (Roper, 1980b). "Thirst" explanations maintain that inter-

I thank the U.K. Science Research Council for financial support, and S. J. Shettleworth and V. LoLordo for comments on the manuscript. Reprints may be obtained from: T. J. Roper, School of Biology, University of Sussex, Brighton BN1 9QG, England. mittent presentation of food reinforcement produces some kind of specific physiological or psychological need for water, for example by stimulating oral dehydration receptors (Stein, 1964), by causing thermoregulatory imbalance (Carlisle, 1971), or by causing insulin release which, in turn, precipitates a fall in blood glucose (Berrios, Carlson, Sawchenko, Gold, \& Mui, 1979; Freed, Zec, \& Mendelson, 1977). “General activation" hypotheses, on the other hand, propose that intermittent reinforcement has a general facilitatory effect on a wide range of activities. This effect is usually described in terms of some variable such as frustration (e.g., Thomka \& Rosellini, 1975), arousal (Killeen, 1975), general motor excitability (Wayner, 1974), or stress (Wallace \& Singer, 1976b). If we could decide which of these two types of hypothesis is correct, we might then be in a better position to formulate a detailed explanation of SIP.

The essential distinguishing feature of the two types of hypothesis is that they make different predictions about the generality of schedule induction. "Thirst" hypotheses, because they focus specifically on the interaction between drinking and food delivery in the rat, predict that drinking should be more or less unique as a schedule-induced activity. "General activation" hypotheses, on the other hand, predict that there should be a wide range of schedule-induced behaviors, and also that schedule induction should occur in species other than the rat, and with reinforcers other than food. Thus, in order to know which type of explanation is most appropriate, we need to know how general the phenomenon of schedule induction is.

Although, at first glance, the literature seems to contain examples of schedule induction across a wide 
range of activities, species, and reinforcers, in practice it is difficult to assess the generality of scheduleinduced behavior, because there is no agreed criterion of schedule induction. The aim of this paper is therefore twofold: first, to clarify the meaning of the term "schedule-induced" and to suggest a criterion whereby schedule induction can be recognized experimentally; and second, to review studies purporting to show that schedule induction extends across a range of behaviors, species, and reinforcers.

\section{Finding a Suitable Baseline for Schedule-Induced Behavior}

Schedule-induced drinking first caught Falk's attention because of the gross amount of water that rats would consume, despite the apparent absence of any physiological need for water or of any contingency between drinking and food reinforcement. The term "schedule-induced" was well chosen, because it implies that the schedule causes the rat to drink more than it would otherwise. The enhancement of drinking beyond its normal frequency of occurrence constitutes the basic unsolved problem of SIP.

Because of the sheer amount of water that rats can be induced to consume, it has always seemed quite clear that SIP involves excess drinking (Falk, 1966, reported a rat's drinking $90 \mathrm{ml}$ of water, equivalent to almost half its body weight, in a single session of intermittent food reinforcement). Induced drinking is also highly reliable by behavioral standards: it occurs in virtually $100 \%$ of subjects and accompanies virtually every food reinforcement even in sessions lasting several hours (Keehn \& Riusech, 1979). Consequently, little critical attention has been given to the question of how to assess the degree to which the schedule of food reinforcement enhances drinking.

With other types of interreinforcement behavior, such as wheel-running, it may not be self-evident that the activity is enhanced by intermittent reinforcement, because the baseline frequency of the behavior may already be high; and whether or not the behavior is enhanced is a vital point, because it is the enhancement of the behavior that constitutes the basic unsolved problem of schedule induction. For example, if we were to find that, under an intermittent schedule of food delivery, a rat engaged in regular interreinforcement wheel-running, but that the same or a greater amount of running occurred when no food was available, we should not need to invoke schedule induction: we should simply conclude that running occurs in hungry rats irrespective of whether or not food is concurrently available.

It follows that, in order to assess whether or not an activity is enhanced by an intermittent schedule, we need some kind of nonschedule baseline for purposes of comparison. Four different types of baseline have been used in studies of schedule-induced behavior, and because they have different strengths and weaknesses it is important to examine them in turn.

Home-cage baselines. Falk (1966) compared the amount of water drunk per session by rats under various fixed-interval (FI) schedules of food reinforcement with the amount drunk per day in the home cage when food and water were freely available. Flory (1971) proposed that a ratio of session intake to 24 -h home-cage intake exceeding 1.0 should be taken as an operational definition of SIP.

There are several problems with this approach, some trivial and others more basic. For example, there is no justification for comparing intake during a session of arbitrary duration with 24 -h home-cage intake; and because food deprivation is known to affect water consumption (Toates, 1979) it is misleading to compare session intake with predeprivation home-cage intake. The most obvious objection, however, is that home-cage behavior is inevitably subject to confounding variables when compared with session behavior: for example, the type of food available to the animal is usually different. It is clearly preferable, therefore, to use a baseline procedure conducted in the experimental apparatus.

Free-reinforcer or FR 1 baselines. Various investigators have compared the amount of behavior occurring under an intermittent schedule of reinforcement with the amount occurring when the reinforcer is freely available, or available according to a fixedratio (FR) 1 schedule, in the test apparatus (Carlisle, Shanab, \& Simpson, 1972; Hudson \& Singer, 1979; Keehn \& Colotla, 1970; Roper, 1978). There are two problems with this procedure. First, it is impossible to equate both session duration and number of reinforcements per session between an intermittent and an FR 1 schedule, because reinforcement rate is necessarily lower in the former condition than in the latter (Roper, 1980a). Therefore, in order to control for possible nonstationarity in the behavior under investigation, it is necessary to conduct two freereinforcer or FR 1 baselines: one in which the same total number of reinforcements is available in both intermittent and baseline conditions, and in which the baseline session is therefore shorter; and one in which session duration is the same in both conditions, and in which more reinforcements are therefore available in the baseline condition. It is perfectly possible to conduct both types of free-reinforcer baseline (Roper, 1980a), but it is tedious.

The second problem is that free-reinforcer or FR 1 procedures allow the animal to engage in more or less continuous consumatory behavior, so that no time is available for the potential schedule-induced activity. Consequently, if more of the activity in question occurs under an intermittent schedule than under the baseline condition, this may simply be because the activity cannot compete with consumatory behavior. 
This problem has been overlooked in the case of SIP, because drinking does occur with appreciable frequency when hungry rats are given free access to food; but other activities may not be linked with eating in the same way. For example, if a hungry rat is given concurrent free access to food and to a running wheel, it will eat more or less continuously and ignore the wheel; and if food is then presented intermittently, a higher rate of running is observed due to the occurrence of running during interreinforcement intervals (Roper, 1978). However, several studies have shown that, in an extinction condition, rate of running is as high as it is under intermittent food reinforcement (Penney \& Schull, 1977; Staddon \& Ayres, 1975; Wetherington, Brownstein, \& Shull, 1977). In this case, then, the intermittent schedule does not induce running; rather, free availability of food suppresses running because of competition from eating. It follows that a free-reinforcer or FR 1 baseline on its own is useless as an indicator of schedule induction.

Extinction baselines. As already noted, a number of investigators (Penney \& Schull, 1977; Staddon \& Ayres, 1975; Wetherington, Brownstein, \& Shull, 1977) have compared the rate of wheel-running in rats under intermittent schedules of food reinforcement with the rate of running in extinction. If an activity is no more frequent under an intermittent schedule than it is in extinction, there are no grounds for referring to the activity as "schedule-induced," because the schedule does not enhance the overall frequency of the activity (Staddon, 1977).

If, on the other hand, the activity occurs at a higher rate under an intermittent schedule than in extinction, are we justified in concluding that the behavior is schedule-induced? Clearly not, because the higher rate of behavior in the former condition might be due merely to the presence of the reinforcer rather than to the schedule of reinforcement. For example, in rats, drinking occurs at a higher rate when food is present than when it is absent, because eating elicits drinking. Thus, an extinction condition alone does not provide an unambiguous baseline for the assessment of schedule induction, although it is informative when combined with a free reinforcer or FR 1 baseline (see above) or a massed-reinforcer baseline (see below).

Massed-reinforcer baselines. As already discussed, it is impossible, with a free reinforcer or FR 1 baseline, to provide simultaneously both the same number of reinforcements per session and the same session duration as are used in an intermittent schedule condition. The massed reinforcer procedure is an attempt to overcome this problem. At the beginning of the session, the animal is presented with a given quantity of the reinforcer and is allowed to engage in consumatory behavior at whatever rate it chooses. Once this quantity of reinforcer has been consumed, the animal is effectively left in a condition of time-out for the rest of the session. In the corresponding intermittent condition, the same total amount of reinforcer is delivered, but in the form of discrete reinforcements intermittently scheduled throughout the session. Thus, amount of reinforcer available and amount of time are the same in both conditions.

Because it controls simultaneously for both variables, a massed-reinforcer baseline constitutes the best single test for schedule-induction. However, it is possible to imagine an activity occurring at a higher rate under intermittent reinforcement than in a massedreinforcer baseline condition, but at a higher rate still in an extinction condition; and if this happened, it would be misleading to describe the activity as "schedule-induced." (This example is not entirely hypothetical: preliminary evidence from our laboratory suggests that the rate of wheel-running varies in this way with water as reinforcer.) Therefore, in order to provide unambiguous evidence of schedule induction, a massed-reinforcer baseline needs to be accompanied by an extinction baseline. This is an important point, because most investigators seem to regard a massed-reinforcer baseline alone as an adequate control procedure.

To conclude, there is no single satisfactory baseline against which to measure schedule-induced behavior. The best combination of baselines is a massed reinforcer and an extinction condition.

\section{Finding the Most Suitable Measure of Schedule-Induced Behavior}

Following the example of Falk (1961, 1966), investigators of schedule-induced drinking have typically reported drinking in the form of water consumed per food reinforcement or per session. Investigators of schedule-induced aggression, by contrast, have used as their measure of behavior the number of aggressive responses per unit time. Other measures of schedule-induced behavior, such as number of bouts per session or average bout duration, have also appeared in the literature. Is any of these measures more appropriate than the others for the assessment of schedule induction?

Considering first the two standard measures of SIP, it is immediately apparent that amount of water drunk per session will vary with session duration. Amount of water drunk per food reinforcement is therefore preferable, because it allows the results of different studies to be compared directly.

I have argued elsewhere, however, that overall rate of behavior is a more appropriate measure than amount of behavior per reinforcement (Roper, 1980a). The argument is as follows. In a typical parametric investigation of SIP, animals are allowed a fixed number of reinforcements per session under a range of schedules and water consumption is reported as 
amount drunk per reinforcement or per session (Allen \& Kenshalo, 1976; Falk, 1966; Flory, 1971; Keehn \& Colotla, 1971). Drinking is said to be "scheduleinduced" because more water is drunk under certain intermittent schedules than under an FR 1 schedule. However, since, in experiments of this type, the number of reinforcements per session is held constant, session duration necessarily varies inversely with reinforcement rate. Hence, rather than affecting water intake directly by imposing low rates of reinforcement, intermittent schedules may result in excessive consumption of water because they prolong feeding, and hence food-associated drinking, in time. Only if the rat's rate of water intake per unit time were enhanced by intermittent schedules of food reinforcement would there be grounds for invoking schedule induction. In fact, rate of drinking in rats is enhanced by a limited range of FI schedules of food reinforcement (Roper, 1980a).

This argument in favor of a rate measure of induced behavior only applies when an FR 1 baseline is used for purposes of comparison. With a massedreinforcer baseline, in which session duration and number of reinforcements are both held constant, overall rate of induced behavior and amount of induced behavior per reinforcement are directly related. With an extinction baseline, another argument in favor of a rate measure appears, namely, that the amount of behavior per reinforcement is meaningless.

A quite different measure of induced behavior is the number of bouts of drinking or, more precisely, the percentage of interreinforcement intervals in which drinking occurs. This score has also been shown to be enhanced by intermittent schedules of food reinforcement (Allen \& Kenshalo, 1978; Roper \& Posadas-Andrews, 1981). Although it may be of interest to know how the temporal distribution of induced behavior within the session varies as a function of schedule, the mere fact that the number of bouts of induced behavior is greater under an intermittent schedule than in a massed-food baseline condition does not necessarily constitute evidence of schedule induction. This is because periodic presentation of a reinforcer would be expected to increase the number of bouts of other activities, by repeatedly causing the animal to interrupt whatever it is doing. In recognition of this point, some authors have coined such terms as "schedule-modulated" (Wetherington \& Brownstein, 1979) or "schedule-controlled" (Keehn \& Riusech, 1979), to apply to behaviors whose temporal pattern of occurrence within the session is altered by schedules of reinforcement, but whose overall rate remains unchanged.

\section{A Working Definition of Schedule-Induction}

The argument so far is that in order to find out whether or not an activity is schedule-induced, it is preferable to conduct a combination of baseline con- ditions and to adopt a rate measure (amount of behavior per hour or per minute averaged over the session) of the activity in question. It is probably neither necessary nor desirable to insist upon a rigid operational definition of schedule induction, but, given the confusion about terminology that exists in the literature, it may be helpful to formulate a working definition that calls attention to the essential features of the phenomenon. I tentatively suggest the following: An activity, other than an operant response, ${ }^{2}$ is said to be schedule-induced if its overall rate of occurrence under an intermittent schedule of reinforcement or under noncontingent intermittent presentation of a reinforcer exceeds its rate of occurrence (1) under a massed-reinforcer baseline condition in which the same total amount of reinforcer is freely available in a session of the same duration, and (2) under an extinction condition in which no reinforcer is scheduled at any time within the session. In the following discussion, I shall use the term "schedule-induced" in this restricted sense.

Since some activities (wheel-running and grooming, see below) occur reliably during interreinforcement intervals but are not enhanced by comparison with suitable baseline procedures, a separate term is needed to describe noninduced interreinforcement behavior. Staddon (1977) has proposed the term "facultative behavior" for such cases. It is also useful to have a generic term for both schedule-induced and facultative behavior, and Falk's early term "adjunctive behavior" is well suited to this purpose (Falk, 1971). The term "collateral behavior" (Richardson \& Loughhead, 1974) seems to be another generic term for nonoperant interreinforcement behavior, but has proved less popular than "adjunctive behavior."

\section{How General is Schedule Induction?}

We can now ask whether the phenomenon of schedule induction is specific to drinking in the rat under intermittent schedules of food reinforcement or whether it occurs with other behaviors, species, and reinforcers.

The list of activities that occur during interreinforcement intervals is undoubtedly long. Besides water-drinking, it includes: drinking of air, alcohol, and various other solutions; wheel-running; woodchewing; attacking a conspecific; drug injection; locomotor behavior; manipulation and ingestion of litter material ("pica"); eating; grooming; escape; various idiosyncratic stereotyped activities such as tail-biting; and, in humans, cigarette smoking. The species involved in these studies include, besides the rat, various other species of laboratory and wild rodents, pigeons, various nonhuman primates, and humans; and the reinforcers include water, wheelrunning, visual stimuli, and game-playing, as well as food. 
On the basis of this evidence, most investigators assume that schedule induction is of wide generality (e.g., Wallace \& Singer, 1976a). However, this conclusion is not justified, because very few studies of adjunctive activities other than drinking have included adequate (or even inadequate) baseline conditions against which to assess schedule induction. Thus, although there is no doubt that the occurrence of adjunctive behavior is widespread, the question of schedule induction remains largely a matter of speculation. Nevertheless, a selective review of the literature may be useful for three reasons: (1) to emphasize how scanty is the evidence concerning schedule induction; (2) because in a few cases there is evidence of the induction of activities other than drinking; and (3) because in a few cases there is evidence, sometimes quite compelling, of noninduction. The cases that have been relatively well investigated are as follows:

Aggression in pigeons. With the exception of drinking in rats, aggression in pigeons is the most thoroughly investigated adjunctive activity (Staddon, 1977). Remarkably, however, only two of the many studies of what is routinely referred to as "schedule-induced aggression" include any type of baseline procedure, and the results of these two studies are contradictory. Yoburn and Cohen (1979a) compared aggression under an FT schedule of food presentation with aggression in an extinction condition, in three pigeons, and found little difference in attack rate between the two conditions. On the other hand, Yoburn and Cohen (1979b) reported somewhat greater attack rates in four birds under various fixed-time (FT) schedules than in massed-food or extinction conditions. Thus, there is some reason to suppose that aggression in pigeons is schedule-induced, but one could wish for better evidence. In any case, adjunctive aggression seems to be a weak and variable behavior compared with induced drinking in rats: it is slow to appear when intermittent reinforcement is introduced, and a substantial proportion of subjects fail to show it.

Wheel-running in rats. In an early paper, Levitsky and Collier (1968) reported induction of running in rats under a VI schedule of food reinforcement, by comparison with FR 1 and extinction baselines. However, this result, which is difficult to evaluate because of the small number of subjects and the brevity of the report, has subsequently proved unrepeatable: Staddon and Ayres (1975) found that number of wheel turns per session was no greater under an FT schedule than in extinction; Penney and Schull (1977) and Wetherington, Brownstein, and Shull (1977) found no enhancement of running under FI or FT schedules relative to massed-food and extinction conditions; and Edwards (Note 1) failed to find enhancement of running in a series of experiments using a variety of FI and FT schedules, massed- food and extinction conditions, and different types of apparatus. Thus, the majority of evidence suggests that wheel-running is a facultative behavior with food reinforcement.

King (1974) found that rats ran more under an FT schedule of water presentation than in a massedwater condition. This result was statistically significant and has subsequently been replicated in our laboratory, but we found that an extinction condition revealed higher rates of running than were observed in either the FT or the massed-water condition (unpublished results). Thus, running may not be a schedule-induced activity with water reinforcement, despite King's result.

Drug injection in rats. Singer and others have investigated what they term "schedule-induced selfinjection" (Lang, Latiff, McQueen, \& Singer, 1977; Oei \& Singer, 1979; Oei, Singer, Jeffreys, Lang, \& Latiff, 1978; Takahashi, Singer, \& Oei, 1978). Their method is to allow rats to leverpress for drug injection on an FR 1 schedule, either in the presence of a concurrent FT schedule of food reinforcment or in a no-food control condition. With some drugs (nicotine, heroin, methadone, and ethanol), rate of selfinjection is reliably higher under an FT schedule than in an extinction condition, suggesting schedule induction.

These interesting studies constitute the best evidence yet available of induction of an activity other than drinking. However, they require extension in at least one important respect: as already noted, an unambiguous demonstration of schedule induction requires a massed-food as well as an extinction baseline. Apart from this methodological shortcoming, induced self-injection is difficult to evaluate because schedule induction is confounded with the process of addiction to the drug (leverpressing for self-injection of saline cannot be induced by FT schedules of food presentation). This does not invalidate the claim that schedule induction is occurring, but it does mean that another process is present which might accelerate schedule induction.

Eating in rats. Several authors (King, 1974; Myerson \& Christiansen, 1979; Taylor \& Lester, 1969; Wetherington \& Brownstein, 1979) have failed to obtain induced eating in rats under FI or FT schedules of water reinforcement, using, for purposes of comparison, extinction, massed-water, and FR 1 control conditions.

Drinking in species other than the rat. As already noted, schedule-induced drinking is a highly reliable phenomenon in laboratory rats. No difficulty has been encountered in obtaining induced drinking of comparable magnitude in primates (Allen \& Kenshalo, 1976, 1978; Barrett, Stanley, \& Weinberg, 1978), but the effect is less certain in a number of species.

Shanab and Peterson (1969) reported SIP in a single pigeon under various FI and VI schedules of food 
reinforcement, but the data given were extremely sparse and the only baseline used was an FR 1 condition. Against this equivocal result, Dale (1979), Miller and Gollub (1974), Whalen and Wilkie (1977), and Yoburn and Cohen (1979b) all report failure to obtain reliable adjunctive drinking in pigeons under a variety of FI and FT schedules. In these studies, postreinforcement drinking does seem to have occurred, but only after a very small percentage of reinforcements.

In guinea pigs, adjunctive drinking exceeds that shown by pigeons but is still less reliable than it is in rats (Freed, Zec, \& Mendelson, 1977; Porter, Sozer, \& Moeschl, 1977; Urbain, Poling, \& Thompson, 1979). Whether or not drinking is schedule-induced in this species remains an open question: suitable baseline conditions have not been conducted. Induced drinking occurs in some strains of mice, relative to a massed-food control condition (Palfai, Kutscher, \& Symons, 1971), but not in all strains (Symons \& Sprott, 1976). Wilson and Spencer (1975) report failure to obtain induced drinking in hamsters, although one of their four subjects did show moderately high levels of drinking under a VI schedule of food reinforcement. No attempt was made to assess baseline level of drinking. Hoppmann and Allen (1979) obtained reliable adjunctive drinking in only one of five wild-caught rats, and Porter, Hastings, and Pagels (1980) did so in only one of three wildcaught cotton rats.

For gerbils, the literature is particularly contradictory. Porter and Bryant (1978a) and Wilson and Spencer (1975) were unable to obtain adjunctive drinking at all, whereas Porter and Bryant (1978b) obtained induced drinking in three gerbils under an FT 3-min schedule of food presentation. The drinking in this case occurred after a high proportion of food reinforcements, and in all respects strongly resembled SIP in rats. Porter and Bryant (1978b) attribute their success to the use of a long (3-min) interreinforcement interval, but we have subsequently failed to repeat their result using the same or a longer interval (Roper \& Edwards, Note 2).

In summary, schedule-induced drinking occurs with noteworthy reliability in laboratory rats (albino, hooded, and Irish), various nonhuman primates, and some strains of mice; and it may occur in guinea pigs, hamsters, gerbils, wild-caught rats, and cotton rats, but more evidence is needed. There is very little evidence of its occurrence in pigeons.

Other possible cases of schedule induction. A number of authors have reported adjunctive wood-chewing in rats under intermittent schedules of food reinforcement (Killeen, 1975; Laties, Weiss, \& Weiss, 1969; Roper, 1978), but in none of these studies was there adequate assessment of baseline rate of chewing. In a number of experiments using FI schedules, Roger and Crossland (in press) have obtained wood- ing. In a number of experiments using FI schedules, Roper and Crossland (Note 3) have obtained woodchewing which is enhanced relative to massed-food and extinction baselines. However, chewing in these experiments has proved unreliable in comparison with schedule-induced drinking: it occurs in a relatively small proportion of interreinforcement intervals, tends to decline within the session, and fails to appear at all in some subjects.

There have been several attempts to obtain induced drinking in rats using brain stimulation as reinforcer. Three of these (Cohen \& Mendelson, 1974; Ramer \& Wilkie, 1977; Wayner, Greenberg, Fraley, \& Fisher, 1973) failed absolutely. Atrens (1973) obtained reliable drinking at first, but the behavior disappeared during 2 weeks of testing. Cantor and Wilson (1978), on the other hand, obtained substantially more drinking under FI and FR schedules of brain stimulation than under FR 1 or extinction conditions. Induced drinking with brain stimulation as reinforcer thus appears difficult, but not impossible, to obtain.

There are two other studies that go some way towards demonstrating schedule induction. Hudson and Singer (1979) reported induced drinking in two of three macaques using visual stimuli (opportunity to view either a film or a conspecific) as reinforcer, with free-reinforcer and extinction baselines. The second study was by Muller, Crow, and Cheney (1979) and involved adjunctive motor activity in humans. In college students, activity was no higher during an FT schedule for poker-chip reinforcement than in extinction, but in two retarded children, an FT schedule did produce reliably higher levels of activity consisting of stereotyped movements, such as rocking. These interesting studies deserve replication with massed-reinforcer baselines.

Other cases of noninduction. Roper (1980b) observed activities such as grooming, locomotor activity, and rearing in rats under FT schedules of food and water delivery, and in extinction and massedreinforcer conditions. Certain activities (e.g., rearing with water reinforcement) were enhanced by FT schedules, but these activities all occurred towards the end of the interreinforcement interval and hence were probably superstitious. In no case was a postreinforcement activity found to be schedule-induced. Roper and Nieto (1979) failed to obtain induced grooming in nondeprived rats under an FT schedule of food delivery using, for purposes of comparison, a massed-food control.

\section{Conclusions}

According to the evidence reviewed above, the most likely examples of schedule-induced behavior, other than drinking in rats and primates, are aggression in pigeons and drug self-injection in rats. Further confirmation is needed, however, in both cases, and self-injection may be atypical because of the factor 
of addiction. With certain other activities (woodchewing in rats with food reinforcement; drinking in various species other than rats and primates), there is some evidence of induction, but these activities are, at best, weaker and more variable than is scheduleinduced drinking in rats. In yet other cases (wheel running and grooming in rats with food reinforcement, eating in rats with water reinforcement), attempts to obtain schedule induction have produced negative results, suggesting that these are facultative activities.

It would be premature to conclude from these results that drinking is unique as a schedule-induced activity, but it is equally premature to conclude, as many investigators have done, that schedule induction is of widespread generality (Falk, 1971, 1977; Porter, Hastings, \& Pagels, 1980; Wallace \& Singer, 1976a; Wayner, 1974). What is needed is further research that pays attention to the need for adequate baseline procedures, plus a willingness on the part of editors to accept for publication negative results (many failures to obtain schedule induction have probably not found their way into the literature, while conversely there are numerous published claims to have observed schedule induction in cases in which the evidence is in fact negligible). Systematic research is also required into the factors that affect the frequency of schedule-induced behavior: it may well turn out that failures to observe schedule induction have resulted from trivial methodological shortcomings, such as inappropriate schedules or levels of deprivation. If, on the other hand, we find that schedule induction really is a relatively rare phenomenon, then it will be clear what sort of explanation of SIP we should look for: namely, an explanation that focuses on the interaction between feeding and drinking in the laboratory rat and a few other species rather than an explanation involving concepts such as frustration, arousal, or stress.

\section{REFERENCE NOTES}

1. Edwards, E. Adjunctive wheel-running in rats and gerbils. Doctoral dissertation, University of Cambridge, in preparation, 1981.

2. Roper, T. J., \& Edwards, E. Adjunctive wheel-running and drinking in gerbils. Manuscript in preparation, 1981.

\section{REFERENCES}

Allen, J. D., \& Kenshalo, D. R., JR. Schedule-induced drinking as a function of interreinforcement interval in the rhesus monkey. Journal of the Experimental Analysis of Behavior, 1976, 26, 257-267.

Allen, J. D., \& Kenshalo, D. R. Schedule-induced drinking as functions of interpellet interval and draught size in the Java macaque. Journal of the Experimental Analysis of Behavior, 1978, 30, 139-151.

Atrens, D. M. Schedule-induced polydipsia and polyphagia in nondeprived rats reinforced by intracranial stimulation. Learning and Motivation, 1973, 4, 320-326.
Barrett, J. E., Stanley, J. A., \& Weinberg, E. S. Scheduleinduced water and ethanol consumption as a function of interreinforcement interval in the squirrel monkey. Physiology \& Behavior, 1978, 21, 453-455.

Berrios, N., Carlson, N. R., Sawchenko, P. E., Gold, R. M., \& MuI, A. H. Insulinogenic mediation of schedule induced polydipsia? Physiology \& Behavior, 1979, 23, 237-240.

Cantor, M. B., \& WILson, J. F. Polydipsia induced by a schedule of brain stimulation reinforcement. Learning \& Motivation, $1978,9,428-445$.

Carlisle, H. J. Fixed-ratio polydipsia: Thermal effects of drinking, pausing and responding. Journal of Comparative and Physiological Psychology, 1971, 75, 10-22.

Carlisle, H. J., Shanab, M. E., \& Simpson, C. W. Scheduleinduced behaviors: Effect of intermittent water reinforcement on food intake and body temperature. Psychonomic Science, 1972, 26, 35-36.

Cohen, I. L., \& MEndelson, J. Schedule-induced drinking with food, but not ICS, reinforcement. Behavioral Biology, 1974, 12, 21-29.

DAle, R. H. I. Concurrent drinking by pigeons on fixed-interval reinforcement schedules. Physiology \& Behavior, 1979, 23, 977-980.

FALK, J. L. Production of polydipsia in normal rats by an intermittent food schedule. Science, 1961, 133, 195-196.

FALK, J. L. Schedule-induced polydipsia as a function of fixed interval length. Journal of the Experimental Analysis of Behavior, $1966,9,37-39$.

FALK, J. L. Conditions producing psychogenic polydipsia in animals. Annals of the New York Academy of Sciences, 1969, 157, 569-593.

FALK, J. L. The nature and determinants of adjunctive behavior. Physiology \& Behavior, 1971, 6, 577-588.

FALK, J. L. The origin and functions of adjunctive behavior. Animal Learning \& Behavior, 1977, 5, 325-335.

Flory, R. K. The control of schedule-induced polydipsia: Frequency and amount of reinforcement. Learning and Motivation, 1971, 2, 215-227.

Freed, W. J., Zec, R. F., \& Mendelson, J. Schedule-induced polydipsia: The role of orolingual factors and a new hypothesis. In J. A. W. M. Weijnen \& J. Mendelson (Eds.), Drinking behavior: Oral stimulation, reinforcement and preference. New York: Plenum Press, 1977.

Hoppmann, R. A., \& Allen, J. D. A test of the generality of schedule-induced polydipsia to wild-caught Norway rats. Physiology \& Behavior, 1979, 22, 195-198.

Hudson, R., \& Sinaen, G. Polydipsia in the monkey generated by visual display schedules. Physiology Behavior, 1979, 22, 379-381.

KeEHN, J. D., \& Colotla, V. A. Prediction and control of schedule-induced drink durations. Psychonomic Science, 1970, 21, 147-148.

KeEHN, J. D., \& Colotha, V. A. Schedule-induced drinking as a function of interpellet interval. Psychonomic Science, 1971, 23, 69-71.

KeEhN, J. D., \& RiUsech, R. Schedule-induced drinking facilitates schedule-controlled feeding. Animal Learning \& Behavior, $1979,7,41-44$.

KILleEN, P. On the temporal control of behavior. Psychological Review, 1975, 82, 89-115.

Kina, G. D. Wheel running in the rat induced by a fixed-time presentation of water. Animal Learning \& Behavior, 1974, 2, 325-328.

Lana, W. J., Latiff, A. A., McQueen, A., \& Singer, G. Self administration of nicotine with and without a food delivery schedule. Pharmacology, Biochemistry \& Behavior, 1977, 7, 65-70.

Laties, V. G., Weiss, B., \& Weiss, A. B. Further observations on overt "mediating" behavior and the discrimination of time. Journal of the Experimental Analysis of Behavior, 1969, 12, 43-57. 
Levitsky, D., \& Collier, G. Schedule-induced wheel running. Physiology \& Behavior, 1968, 3, 571-573.

Mille R, J. S., \& Gollub, L. R. Adjunctive and operant boltpecking in the pigeon. Psychological Record, 1974, 24, 203-208.

Mulle r, P. G., Crow, R. E., \& Cheney, C. D. Schedule-induced locomotor activity in humans. Journal of the Experimental Analysis of Behavior, 1979, 31, 83-90.

Myerson, J., \& Christiansen, B. Temporal control of eating on periodic water schedules. Physiology \& Behavior, 1979, 23, 279-282.

OEi, T. P. S., \& Singer, G. Effects of a fixed time schedule and body weight on ethanol self-administration. Pharmacology, Biochemistry \& Behavior, 1979, 10, 767-770.

Oei, T. P. S., Singer, G., Jeffreys, D., Lang, W., \& Latiff, A. Schedule induced self injection of nicotine, heroin and methadone by naive animals. In F. C. Colpeart \& J. A. Rosecrans (Eds.), Stimulus properties of drugs: Ten years of progress. Amsterdam: Elsevier/North-Holland Biomedical Press, 1978.

Palfai, T., Kutscher, C. L., \& Symons, J. P. Schedule-induced polydipsia in the mouse. Physiology \& Behavior, 1971, 6, 461-462.

Penney, J., \& Schull, J. Functional differentiation of adjunctive drinking and wheel running in rats. Animal Learning \& Behavior, 1977, 5, 272-280.

Porter, J. H., \& Bryant, W. E. Adjunctive behavior in the Mongolian gerbil. Physiology \& Behavior, 1978, 21, 151-155. (a)

Porter, J. H., \& Bryant, W. E. Acquisition of schedule-induced polydipsia in the Mongolian gerbil. Physiology \& Behavior, 1978, 21, 825-827. (b)

Porter, J. H., Hastings, M. T., \& Pagels, J. F. Scheduleinduced polydipsia in the cotton rat (Sigmodon hispidus). Bulletin of the Psychonomic Society, 1980, 16, 15-18.

Porter, J. H., Sozer, N. N., \& Moeschl, T. P. Scheduleinduced polydipsia in the guinea pig. Physiology \& Behavior, $1977,19,573-575$.

Ramer, D. G., \& Wilkie, D. M. Spaced food but not electrical brain stimulation induces polydipsia and air licking. Journal of the Experimental Analysis of Behavior, 1977, 27, 507-514.

Richardson, W. K., \& Lovghead, T. E. The effect of physical restraint on behavior under the differential-reinforcement-oflow-rate schedule. Journal of the Experimental Analysis of Behavior, 1974, 21, 455-461.

ROPER, T. J. Diversity and substitutability of adjunctive activities under fixed-interval schedules of food reinforcement. Journal of the Experimental Analysis of Behavior, 1978, 30, 83-96.

ROPER, T. J. Changes in rate of schedule-induced behaviour in rats as a function of fixed-interval schedule. Quarterly Journal of Experimental Psychology, 1980, 32, 159-170. (a)

ROPER, T. J. Behaviour of rats during self-initiated pauses in feeding and drinking, and during periodic response-independent delivery of food and water. Quarterly Journal of Experimental Psychology, 1980, 32, 459-472. (b)

Roper, T. J., \& Crossland, G. Schedule-induced woodchewing in rats and its dependence on body weight. Animal Learning \& Behavior, in press.

Roper, T. J., \& Nieto, J. Schedule-induced drinking and other behavior in the rat, as a function of body-weight deficit. Physiology \& Behavior, 1979, 23, 673-678.

Roper, T. J., \& Posadas-Andrews, A. Are schedule-induced and displacement activities causally related? Quarterly Journal of Experimental Psychology, 1981, 33B, 181-193.

Segal, E. F. Induction and the provenance of operants. In R. M. Gilbert \& J. R. Milleson (Eds.), Reinforcement: Behavioral analyses. New York: Academic Press, 1972.

Shanab, M. E., \& Peterson, J. L. Polydipsia in the pigeon. Psychonomic Science, 1969, 15, 51-52.

Staddon, J. E. R. Schedule-induced behavior. In W. K. Honig \& J. E. R. Staddon (Eds.), Handbook of operant behavior. New York: Prentice-Hall, 1977.

Staddon, J. E. R., \& Ayres, S. L. Sequential and temporal properties of behavior induced by a schedule of periodic food delivery. Behaviour, 1975, 54, 26-49.
StEIN, L. Excessive drinking in the rat: Superstition or thirst? Journal of Comparative and Physiological Psychology, 1964, $58,237-242$.

Symons, J. P., \& Sprott, R. L. Genetic analysis of schedule induced polydipsia. Physiology \& Behavior, 1976, 17, 837-839.

Takahashi, R. N., Singer, G., \& OEi, T. P. S. Schedule-induced self injection of d-amphetamine by naive animals. Pharmacology, Biochemistry \& Behavior, 1978, 9, 857-961.

TAYLOR, D. B., \& LESTER, D. Schedule-induced nitrogen "drinking" in the rat. Psychonomic Science, 1969, 15, 17-18.

Thomka, M. L., \& Rosellini, R. A. Frustration and the production of schedule-induced polydipsia. Animal Learning \& Behavior, 1975, 3, 380-384.

Toates, R. M. Homeostasis and drinking. Behavioral and Brain Sciences, 1979, 2, 95-139.

Urbain, C., Poling, A., \& Thompson, T. Differing effects of intermittent food delivery on interim behavior in guinea pigs and rats. Physiology \& Behavior, 1979, 22, 621-625.

Wallace, M., \& Singer, G. Schedule-induced behavior: A review of its generality, determinants and pharmacological data. Pharmacology, Biochemistry \& Behavior, 1976, 5, 483-490. (a)

Wallace, M., \& Singer, G. Adjunctive behavior and smoking induced by a maze solving schedule in humans. Physiology \& Behavior, 1976, 17, 849-852. (b)

WAyner, M. J. Specificity of behavioral regulation. Physiology \& Behavior, 1974, 12, 851-869.

Wayner, M. J., Greenberg, I., Fraley, S., \& Fisher, S. Effects of $4^{9}$-tetrahydrocannabinol and ethyl alcohol on adjunctive behavior and the lateral hypothalamus. Physiology \& Behavior, 1973, 10, 109-132.

Wetherington, C. L., \& Brownstein, A. J. Schedule control of eating by fixed-time schedules of water presentation. Animal Learning \& Behavior, 1979, 7, 38-40.

Wetherington, C. L., Brownstein, A. J., \& Shull, R. L. Schedule-induced running and chamber size. Psychological Record, 1977, 27, 703-713.

Whalen, T. E., \& Wilkie, D. M. Failure to find scheduleinduced polydipsia in the pigeon. Bulletin of the Psychonomic Society, 1977, 10, 200-202.

Wilson, S., \& Spencer, W. B. Schedule-induced polydipsia: Species limitations. Psychological Reports, 1975, 36, 863-866.

Yoburn, B. C., \& Cohen, P. C. Schedule-induced attack on a pictorial target in feral pigeons (Columbia livia). Bulletin of the Psychonomic Society, 1979, 13, 7-8. (a)

YobuRn, B. C., \& Cohen, P. S. Assessment of attack and drinking in White King pigeons on response-independent food sched. ules. Journal of the Experimental Analysis of Behavior, 1979 , 31, 91-101. (b)

\section{NOTES}

1. Terms such as "intermittent schedule of reinforcement" or "reinforcement delivery" should be understood as referring both to contingent (FI, VI) schedules and to noncontingent (FT; VT) schedules.

2. By "operant response," I mean a response that is explicitly reinforced. Ideally, a definition of schedule induction would also exclude responses that arise through processes of adventitious reinforcement or classical conditioning, because schedule-induced behavior presents a special problem only if it cannot be attributed to these processes. However, since there are no simple criteria whereby adventitiously reinforced or classically conditioned responses may be recognized, such a definition would be difficult to formulate. For evidence that schedule-induced drinking is not adventitiously reinforced or classically conditioned, see Staddon (1977).

(Manuscript received November 25, 1980; revision accepted for publication May 19, 1981.) 